\title{
(242)
}

\section{Health Damage Cost of Rice Processing Industry of the North Central Province}

\author{
Chandrasiri G. N. ${ }^{1}$, Gunawardena U.A.D.P. ${ }^{2 *}$ \\ ${ }^{1}$ Central Environmental Authority, Sri Lanka \\ ${ }^{2}$ Department of Forestry \& Environmental Science, University of Sri Jayewardenepura, Sri Lanka \\ *prasanth@sjp.ac.lk
}

\begin{abstract}
Rice is the staple food for Sri Lankans and rice industry is the largest agro based industry in Sri Lanka. Sri Lanka currently produces 3.8 million metric tons of paddy annually. The total land devoted for paddy is estimated to be about 0.70 Hectares million ha at present. Sri Lanka has around 7,000 rice mills and North Central Province has about 1,000 rice mills. Although the rice industry supplies food for the nation, it generates considerable pollution to three media (air water and soil). Rice mills generate fugitive emissions from various sections during handling of paddy, cleaning and milling of paddy, handling and storage of husk and handling, storage and disposal of boiler ash etc. During wet processing, it generates waste water. Present study attempted to estimate the health damage cost, mainly cost of air pollution from rice processing industry. An isolated rice mill located in Lankapura Divisional Secretariat Division of the Polonnaruwa District was selected to avoid impacts from other industries. The mill had a total daily production capacity of $175 \mathrm{Mt} / \mathrm{d}$ and there were total affected population of 1,599 around the mill. Present study selected 120 households, 30 households each from the distances from $250 \mathrm{~m}, 500 \mathrm{~m}, 750 \mathrm{~m}$ and $1000 \mathrm{~m}$ away from the mill. Both contingent valuation method and human capital approach was adopted for the damage cost estimation. Information on distance to rice mill, health issues due to the mill, monthly health damage costs, monthly income level and willingness to pay for an environmental improvement program to prevent health damage costs were collected using pre tested questionnaire. Twenty eight asthma patients were found in the sample and estimated number in the affected population is 88 patients. Annual health damage cost was estimated from human capital approach is LKR $2,112,000$. Mean willingness to pay for an environmental improvement under the contingent valuation survey was LKR 908.00 per household. The study also discusses implications for policy, especially on providing incentives for pollution control of rice processing industry.
\end{abstract}

Keywords: Health damage cost, Rice mills, Air pollution 